will be hard to eradicate, and reoperations have resulted in substantial morbidity and mortality.

\section{CONCLUSIONS}

The polymerase chain reaction method adds substantially to the etiologic diagnosis of infective endocarditis, leading to institution of the appropriate antibiotic therapy. It should be considered for all patients for whom routine cultures have been negative despite a high index of clinical suspicion of infective endocarditis.

\section{References}

1. Fenollar F, Puéchal X, Raoult D. Whipple's disease. N Engl J Med. 2007;356:55-66

2. Fenollar F, Célard M, Lagier JC, Lepidi H, Fournier PE, Raoult D. Tropheryma whipplei endocarditis. Emerg Infect Dis. 2013;19:1721-30.

3. Amendolara M, Barbarino C, Bucca D, Stevanato G, Zucchelli M, Romano F, et al. Whipple's disease infection surgical treatment: presentation of a rare case and literature review. G Chir. 2013:34:117-21.

4. Geissdörfer W, Moos V, Moter A, Loddenkemper C, Jansen A, Tandler R, et al High frequency of Tropheryma whippley in culture negative endocarditis. J Clin Microbiol. 2012;50:216-22.

5. Baisden BL, Lepidi H, Raoult D, Argani P, Yardley JH, Dumler JS. Diagnosis of Whipple disease by immunohistochemical analysis: a sensitive and specific method for the detection of Tropheryma whipplei (the Whipple bacillus) in paraffin-embedded tissue. Am J Clin Pathol. 2002;118:742-8.

\title{
Successful aortic valve repair after trauma-induced aortic regurgitation
}

\author{
Hassane Abdallah, MD, Alaae Boutayeb, MD, and Gebrine El Khoury, PhD, Brussels, Belgium
}

Posttraumatic aortic valve regurgitation is uncommon, and aortic valve replacement has long been the sole therapeutic solution. Current data, however, suggest that aortic valve repair techniques represent a valuable option, particularly for young patients with favorable anatomic presentation. This article reviews posttraumatic aortic regurgitation and the importance of aortic valve repair techniques as a feasible and effective therapeutic option.

\section{CLINICAL SUMMARY}

We report the case of a 34-year-old man who was injured in a traffic accident. Results of the first evaluation after the accident were normal; however, the patient was seen 3 months later with progressive dyspnea. On physical examination, a new aortic diastolic murmur in the aortic area was heard, with no signs of heart failure. Echocardiographic findings (transthoracic and transesophageal echocardiography) showed an aortic valve prolapse associated with moderate aortic regurgitation (Figure 1, A). The prolapse was caused by a rupture of the right noncoronary commissure. This corresponds to type II regurgitation according to the classification of Boodhwani and associates. ${ }^{1}$

Because of the observed injuries and the young age of the patient, aortic valve repair was proposed. The procedure

\footnotetext{
From the Cardiothoracic and Vascular Surgery Department, Cliniques Universitaires Saint-Luc, Brussels, Belgium.

Disclosures: Authors have nothing to disclose with regard to commercial support.

Received for publication April 8, 2014; revisions received May 18, 2014; accepted for publication May 27, 2014; available ahead of print Aug 12, 2014.

Address for reprints: Hassane Abdallah, MD, 10500 Boulevard de l'Acadie,

820 H4N2V4 Montreal, Canada (E-mail: abdallahhassane@hotmail.com).

J Thorac Cardiovasc Surg 2014;148:e197-8

$0022-5223 / \$ 36.00$

Copyright (c) 2014 by The American Association for Thoracic Surgery

http://dx.doi.org/10.1016/j.jtcvs.2014.05.086
}

was carried out through a median sternotomy and under normothermic cardiopulmonary bypass. After aortic crossclamping, the aorta was opened and the valve inspected. Operative findings confirmed the echocardiographic data (Figure 2, A). The aortic valve repair consisted of a reinsertion of the right noncoronary commissure with a 5-0 Prolene suture (Ethicon, Inc, Somerville, NJ) reinforced with autologous pericardium. In addition to noncoronary cusp shaving, a sub-commissural annuloplasty was also performed with pledgeted $2-0$ braided sutures. The first arm of the suture was passed from the aortic to the ventricular side, in the interleaflet triangle, and it came back out to the aortic side at the same level. Similarly, the second arm was passed just below the first. This annular reduction was calibrated with a 25-mm Hegar dilator and involved all the interleaflet triangles (Figure 2,B).

Postoperatively, all echocardiographic controls showed a good result with no residual regurgitation (Figure 1, $B$ ). The subsequent course was uneventful, and the patient was discharged on the sixth postoperative day with a regimen of aspirin only. Antiplatelet therapy was interrupted after 3 months. At 1-year follow-up, the patient was doing well with trivial aortic regurgitation.

\section{DISCUSSION}

Posttraumatic aortic regurgitation is a rare condition. A report of 546 patients who died after severe blunt chest trauma showed that only $0.73 \%$ of them had an injury to the aortic valve. ${ }^{2}$ These lesions are due mainly to a brutal increase of the intrathoracic pressure during early diastole, when the transaortic gradient is maximal. According to the available data, the noncoronary cusp seems to be the most frequently involved cusp. ${ }^{2,3}$ 

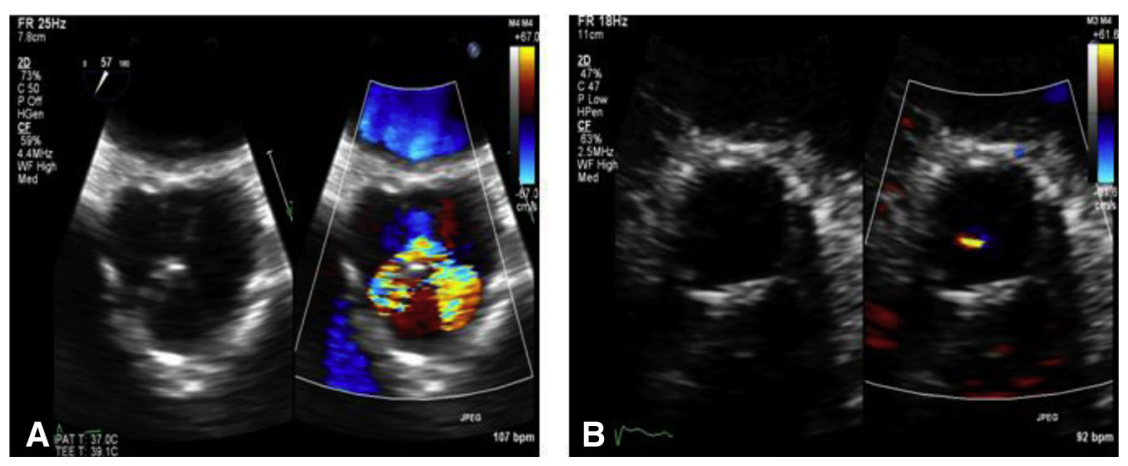

FIGURE 1. A, Preoperative echocardiographic findings showed an aortic valve prolapse associated with moderate aortic regurgitation. B, Postoperative echocardiographic findings showed a good result with no residual regurgitation.

Because of the acute onset, massive regurgitation quickly evolves toward cardiac decompensation. It is probably because of its moderate severity that the aortic insufficiency in our patient was tolerated during a few months. Indeed, whereas Szabo and colleagues ${ }^{3}$ published a similar case of a 47-year-old man with global heart failure 2 months after a violent thoracic trauma, others have reported some patients with acute and intolerable severe regurgitation who underwent urgent surgery.

The management of traumatic aortic regurgitation still remains essentially surgical. The timing depends on the hemodynamic situation, as well as the associated injuries. Despite the good outcomes obtained with the latest generations of biologic prostheses, biologic prosthesis longevity remains lower than that of the mechanical ones, which unfortunately require lifelong anticoagulation, which

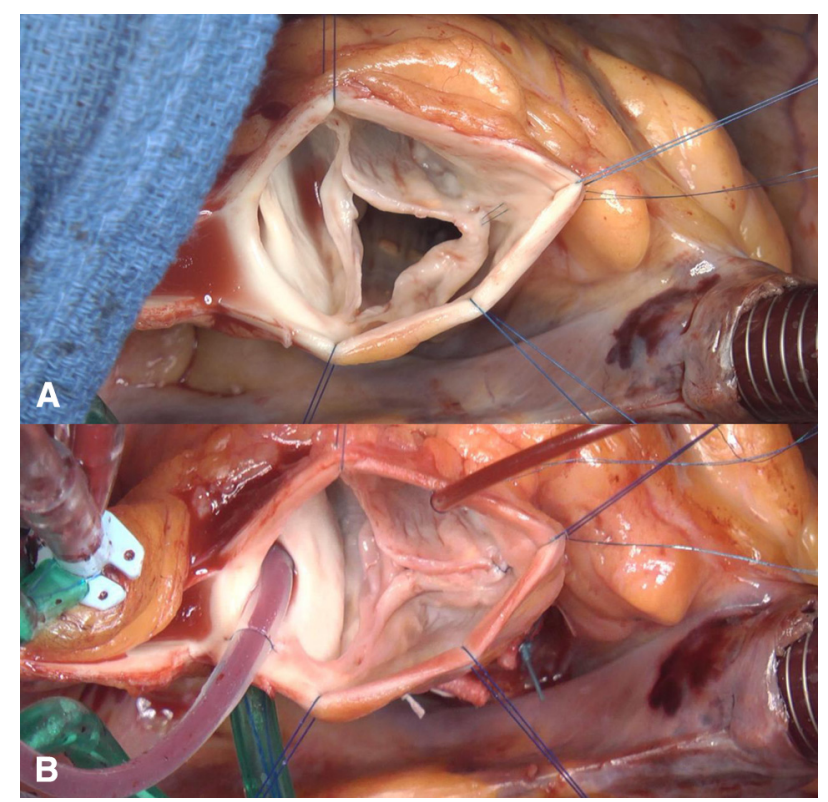

FIGURE 2. A, Operative view showing the rupture of the right noncoronary commissure. B, Final operative view showing the repaired aortic valve. could be associated with significant hemorrhagic risk, especially in a posttraumatic situation. Aortic valve repair thus seems to be an attractive if difficult therapeutic option. These procedures have been abandoned for a long time; however, they have gained a considerable interest thanks to a better understanding of the mechanisms of aortic insufficiency as well as the development of the satisfactory techniques of repair. ${ }^{1}$

The choice of valve replacement or repair should be individually discussed. In addition to the surgeon's capacity, other factors have to be considered. Indeed, it is clear that the emergency cases are far from being the best. Furthermore, the extent of injury, the number of involved cusps or commissures, and the presence of important valvular calcifications or thinning are unfavorable for the success of the procedure. ${ }^{4}$ Our patient underwent a delayed operation. The aortic valve lesions were localized, and the valvular thinning was not compromising. The main goal of the procedure was the reinsertion of the commissure; however, adjunct subcommissural annuloplasty may, in our opinion, stabilize the functional aortic annulus, increase the coaptation surface, and therefore result in better long term durability of the repair. ${ }^{5}$

\section{CONCLUSIONS}

In conclusion, aortic valve repair can be a feasible, safe and effective therapeutic option for posttraumatic aortic regurgitation. Its use can eliminate the drawbacks of valve replacement, whether with a mechanical or a biologic prosthesis.

\section{References}

1. Boodhwani M, de Kerchove L, Glineur D, Poncelet A, Rubay J, Astarci P, et al. Repair-oriented classification of aortic insufficiency: impact on surgical techniques and clinical outcomes. J Thorac Cardiovasc Surg. 2009;137:286-94.

2. Parry GW, Wilkinson GA. Traumatic aortic regurgitation. Injury. 1997;28:679-80.

3. Szabo S, Oikonomopoulos T, Marx R, Hoffmeister HM. Aortic insufficiency due to a partial left-coronary aortic valve prolapse and the detection of two small interatrial jets after blunt thoracic trauma. Int J Cardiol. 2007;119:230-1.

4. Aicher D, Schäfers HJ. Aortic valve repair- current status, indications, and outcomes. Semin Thorac Cardiovasc Surg. 2012;24:195-201.

5. Price J, De Kerchove L, El Khoury G. Aortic valve repair for leaflet prolapse. Semin Thorac Cardiovasc Surg. 2011;23:149-51. 